\title{
The Influence of Coaching Communication towards Self-Efficacy of Teaching in Malaysia Education Organizations
}

\author{
Ling Ying Leh (Corresponding author) \\ School of Educational Studies, Universiti Sains Malaysia \\ 11800 USM, Penang, Malaysia \\ E-mail: lingyingleh@gmail.com \\ Abdul Ghani Kanesan Abdullah \\ School of Educational Studies, Universiti Sains Malaysia \\ 11800 USM, Penang, Malaysia \\ E-mail: agk@usm.my
}

Received: Oct. 16, 2014 Accepted: Nov. 22, $2014 \quad$ Published: November 22, 2014

doi:10.5296/jse.v4i4.6456 URL: http://dx.doi.org/10.5296/jse.v4i4.6456

\begin{abstract}
This study aims to describe the psychometric properties of an instrument for coaching communication that has been adapted and used based on the uniqueness in the workplace culture of education organization in Malaysia. In particular, the objective of this study was to determine the influence of coaching communication on teaching self-efficacy. 251 lecturers from four polytechnics in Sarawak and Penang have been selected randomly to take part in this study. A total of 13 translation items were adapted from the original instrument of coaching communication developed by Heslin, VandeWalle, and Latham (2006) for the purpose of this study. Three factors have emerged initially through exploratory factor analysis on the collected data. It has been explained 88.0 percent on the overall variance. In relation, the reliability for the instrument translated version is 0.978 representing all three factors well as the original instrument by Heslin et al. (2006). It has provided a strong justification to the use of this instrument in educational organizations in Malaysia. Meanwhile, the analysis of the data is done using multiple regression analysis. The findings show that coaching communication
\end{abstract}




\section{Macrothink}

Journal of Studies in Education ISSN 2162-6952

significantly and positively has influence on the teaching self-efficacy. Practically, this study has established acquired organization support to increasing the potential of the followers.

Keywords: Coaching communication, Teaching self-efficacy, Education organization 


\section{Introduction}

There are signs of increasing acceptance internationally where education reforms on a large scale required meeting the challenges of the 21 st century. Thus, the human capital that comes with the quality of skills and competence in the face of an increasingly rapid waves and challenging, educational organizations should play a full role. The existing conventional education models focused on learning outcomes have begun to be questioned. Even academic achievement is and should remain as an important aspect of education, at the same time, the world now requires a holistic approach to the education in the 21 st century. Thus, the human capital equipped with quality skills and competence in facing the rapid and challenging global wave, educational organizations should play their fully role.

Education on 21 st century in educational organizations needs to emphasize feedback delivering to the educators. It is because feedback delivering plays an important role in enhancing the teaching self-efficacy. Reviews of Kopelman (1986) on 72 control experimental studies towards the feedback task reported that feedback improved work behavior in the 68 studies identified. This shows that the feedback contains elements that support learning and are more likely to improve performance significantly (Shea \& Howell, 1999). Therefore, the medium of feedback delivery should be established by the leaders to generate positive psychological situation in the organization. This is in line with the opinion of Shamir, House and Arthur (1993) in which the negative psychological situation occurs when there is no feedback communicated in the organization.

Now coaching has been agreed by the various parties as an effective mechanism to deal with personal change and learning every day. Whitmore (2002) have clarified the coaching successfully empowers the potential of the individual. In other words, the role of coaching is to support the development of students, lecturers, leaders, and educational institutions and to foster a learning culture in the organization. In addition, Wilson (2011) also explained that the guidance can be used to form the individual who is capable of producing. Therefore, leaders must put the focus on developing talent and entertain his followers to pay attention and build their confidence. This is because a successful leader is a leader who is capable of producing and non-producing himself.

However, effective coaching requires two-way communication and trust between leaders and followers. In other words, coaching is seen as a process of mutual interaction between leaders and followers involves the willingness and motivation between the two sides. Ives (2008) considers the coaching as a collaborative interaction and focused, where employers help employees to identify ways to improve performance and tied to personal development. In addition, the coaching encourages employees to find their own solution other than waiting for the employer to tell you what to do.

\section{Coaching Communication in the Workplace}

Coaching culture within the organization is essential to enable the sharing of information is carried out through the process of sending and receiving messages (Raja Roslan, Azizi, \& Mohd. Salleh, 2008). Bacon (2003) and Morgeson (2005) equally believed coaching as daily 
interactions that are used to strengthen the skills of selected with the help of another individual. Therefore, regardless of the hierarchical level leaders should be responsible for implementing coaching culture within the organization; for example, begins with the individual management initiatives and ended the existence of the guidance in the entire organization.

Communication elements should not be ignored in the process guidance. Communication is the pulse of what most discussions of the organization in running the operations of the organization. Sulaiman and Ahmad Khair (2005) has described the communication process begins when the edict rather than the sender or the tool is moved through the typical channels to recipients who later advised to give reply to the message. This element needs to be applied in the process guidance to achieve the understanding between sender and receiver. In addition, if it is not for the purpose of the common good, then it will not form effective communication process (Baharudin \& Mohd Mohd Khairie, 2003).

$\mathrm{Yu}$ (2007) through his research has emphasized the coaching is a critical element in the effective management to enhance productivity and performance. Anyway, not all leaders adopted the coaching in their management roles. They think about the skills, knowledge, and time to coach. However, coaching is not something new and it has always existed in everywhere we are. We have always been an inspiration, support, advice, and motivation to improve the advancement and self-confidence. These elements have been guiding us to make a difference to ourselves.

Fournies study (1999) has put forward the question "Why do not employees do what they are supposed to do" to 25,000 respondents from all over the world. He received the highest response on the question asked where they do not know what should be done by them. This shows that there is a gap between employers and workers in modern organizations today. Organizations expect employees to be able to function properly and independently. In this case, Fournies (1999) has suggested as practical guidance in the organization to correct the problem of communication gap between employers and employees. Basically Fournies (1999) considers the problem should be treated as a change of behavior in the classroom.

Heslin, VandeWalle, and Latham (2006) also identified three basic elements in behavior guidance through literature review made such as guidance, facilitation, and inspiration. According to Heslin et al. (2006), the guidance refers to communication about expectations for job performance clear and constructive feedback on performance and job performance improvement. Further, the facilitation is also helping employees to analyze and explore the problems and strengthen their performance. For inspiration, they saw it as a challenge to its employees to recognize and develop their potential.

Leaders should act as a mentor to integrate series of communication behavior through coaching to ensure learning for continuous problem solving among their followers. Effective coaches must be equipped with the attitudes, skills, and knowledge related. In fact, counselors need confident and act in a professional manner to help coaches improve their performance either personal or work. Thus, coaching communication through this study refers to the behavior of the leaders of his followers to improve job performance through a 
two-way interaction with changing goals become a reality through the use of several options available before executing an action by mutual agreement.

\section{The Influence of Coaching Communication towards Self-Efficacy of Teaching}

Effectiveness of coaching in developing and enhancing self-efficacy has been shown in previous studies (Digman, 2004; Evers, Brouwers, \& Tomic, 2006; Steinwedel, 2001). Digman (2004) conducted a study on 104 executives to explore the impact of executive coaching and mentoring relationship quality on self-efficacy and attitudes related to job satisfaction, organizational commitment, job conflicts, and family conflict. The study found that the quality of the relationship with self-efficacy is high. Moreover, Steinwedel (2001) have reported the effectiveness of self-efficacy and ability to achieve goals in 12 college students who participated in counseling sessions over 16 weeks. The study of Evers et al. (2006) also find guidance effectively enhance self-efficacy in self-set goals among 30 managers Netherlands. Although no previous study has linked teacher self-efficacy to coaching communication, such a link is credible. Teachers who believe they will make a difference are more likely to see coaching communication as an opportunity to expand and consolidate their teaching techniques. In contrast, teachers who see student learning as swamped by uncontrollable forces might regard coaching communication as nothing but more work. Thus, coaching communication is expected to be more likely to have an impact on self-efficacy of teaching in some other ways.

\section{Research Objectives}

The objective of this study was to

(a) Reporting of validity and reliability of assessment instruments of coaching communication in the educational organizations.

(b) Develop a set of items to measure the performance of coaching communication in educational organizations that have been submitted by previous scholars

(c) To carry out Exploratory Factor Analysis (EFA) to assess the factor structure of the items that measure.

(d) Determine the influence of coaching communication towards self-efficacy of teaching.

\section{Research Methodology}

\subsection{Research Design}

The design of this study is descriptive. Azizi, Shahrin, Jamaludin Yusof and Abdul Rahim (2007) describes descriptive research is research that seeks to explain a phenomenon that is happening. This type of research is the type of review. Data obtained using questionnaires were distributed to the respondents represent the population, namely conventional polytechnic lecturers in Penang and Sarawak. All information has been interpreted quantitatively. 


\subsection{Sample}

A total of 251 lecturers working in conventional polytechnic in Penang and Sarawak were randomly selected to participate in the study. This means there are 251 sets of data representing the perception of the General Program or Head of their course. A total of four polytechnics in Malaysia were involved in this study Strathmore (PSP), Polytechnic Balik Pulau (PBU), Polytechnic Kuching Sarawak (PKS), and the Polytechnic Mukah Sarawak (PMS).

\subsection{Instrument}

The instrument consists of a questionnaire prepared to be answered by the respondent. For the purposes of this study, the questionnaire used was adapted to suit the local environment with the permission of the original researchers. There are two parts in this questionnaire. The first part is the respondent seeks to obtain data about the respondent's background. This section consists of four items presented on the respondents' personal information such as gender, highest academic qualification, teaching experience as lecturers, and age on 1 January 2014. For the next part in this survey which aims to identify the coaching communication established by their leaders in helping the followers to improve their performance and develop potential employees. To measure the behavior of leaders through coaching communication, instruments built by Heslin et al. (2006) have referred to and used. Coaching communication in this study as measured by three-dimensional guidance (4 items), facilitation (3 items), and inspiration (3 items), based on seven-point Likert scale ranging from "Never" to "All The Time". This questionnaire was translated into Malay and modified to suit the current environment.

In addition, all of the items from the original questionnaire with double-barreled, length, and flutter have been revised and rewritten based on comments and suggestions from the experts who participated in aspects of content validity. Examples of the original items that "Promote me to explore and try new alternatives" has been modified and translated into two different items on the "Promote me to explore new alternatives" and "Encourage me to try new alternatives".

\subsection{Instrument Translation, Validity, and Reliability of Coaching Communication}

Content validity refers to the extent to which an instrument measures what should be measured (Ary, Mills, \& Airasian, 2010; Chua, 2006). This method is carried out to determine the content of related items and represent variables measured (Flowers, 2006). Content validity of the instruments identified after face validity of the matters to be considered by the researchers themselves and there are no strict rules to ensure the validity of that.

Further, the validity of the content is done by getting reviews and opinions from experts or panel whether the items used to measure the variables studied (Azizi et al., 2007). This means that the content validity of the findings is judgmental to consider the extent to which such instruments meet the standards. Recommendations of experts in the measured need for increase or decrease on the scale are used. 
The original questionnaire was adapted to suit the uniqueness of the local culture. Some of the words in the original version have been changed to new words after obtaining consent from experts in related fields. Items in the original questionnaire were translated from English to Malay translation using back to back translation. This translation is done with the help of three teachers who are experienced in the language for more than 15 years. Then the translated questionnaire was reviewed by a panel of five persons to be appointed to ensure that the translation is not really fulfilling the purpose and confirm it. Expert evaluators' questionnaire consists of four lecturers from local public universities and a senior teacher from the Ministry of Education. They were asked to respond to items on a scale of 1 (Strongly Not Available) to 6 (Very Best) by suitability and accuracy of items in the questionnaire. Reliability of the translated version can be determined using Cronbach's Alpha.

\section{Dimension Determination for Coaching Communication through Exploratory Analysis Factor}

Factor analysis conducted to verify the contents of the instrument and to strengthen the research instrument. Since all of the items in this study were adapted from previous studies, factor analysis can consolidate and strengthen research items.

Content validity of the dimensions of the instrument was carried out through exploratory factor analysis through Principal component analysis (PCA). This analysis was conducted to identify and prioritize the items in the dimensions below a certain variable of the study sample (Tabachnick \& Fidell, 2007).

EFA method is done through repeated rotation (iterations) to form dimensions have distinctive items. EFA methods that have been taken by the researcher as proposed by Meyers, Gamst, and Guarino (2012) are as follows:

(a) The value of Kaiser-Meyer-Olkin (KMO) in the range more than 0.90 is considered a brilliant; 0.80 boast; 0.70 more than usual; 0.60 regular; 0.50 disappointing; and a value of less than 0:50 should not be accepted to carry out factor analysis.

(b) The value of $p<0.05$ in Bartlett's Test of Sphericity for measuring correlation between the items and wanted to provide evidence of significant variables are independent and suitable for factor analysis.

(c) The eigenvalues are more than one is significant for each factor.

(d) The percentage of variance explained must be at least 60 percent of the total variance.

(e) Significant loading factor must be 0.3 and above. Items that have a loading factor of less than 0.3 or a cross-loading are not maintained.

\section{Research Findings}

\subsection{Respondent Demographic Distribution}

In terms of demographic distribution, a total of four items were used as gender, the highest academic qualification, teaching experience as lecturers, and age on 1 January 2014 A total of 251 respondents took part in the study. They consisted of 104 male lecturers of 41.4 per cent 
and 147 female lecturers of 58.6 percent. This has given an overview of the general teaching population among lecturers by gender. For the highest academic qualification anyway, finding shows majority respondents have bachelor degree with 162 people or 64.5 percent. It also gives an idea of where the polytechnic require more higher education qualification among the lecturers. In terms of age on January 1, 2014, the respondents were divided into three age categories. The findings showed that the majority of respondents i.e. 55.9 percent of 140 respondents in the age category are 25 to 32 years. Furthermore, the findings also showed that the majority of respondents have teaching experience ranging from 1 to 11 years, which are 210 people or 84.0 per cent.

This study focuses on three dimensions in coaching communication - guidance, facilitation, and inspiration. Based on the following table, found inspiration dimension showed the highest mean score $(\mathrm{M}=4.605 ; \mathrm{SD}=1.437)$, followed by the dimensions of facilitation $(\mathrm{M}=$ 4.599; $\mathrm{SD}=1413)$ and guidance $(\mathrm{M}=4.345 ; \mathrm{SD}=1.367)$.

\subsection{Findings of Content Validity Analysis}

Initial findings derived from these five experts have suggested the items bring confusion need to be corrected. Changes are made mainly in terms of word usage and sentence structure to make it more easily understood by the respondents. Items that are long and repetitive, and double-barreled have been revised and rewritten.

The next phase is the result of the analysis of five experts showed the coefficients of all the items is above 67.5 percent, while the overall validity coefficient is 87.4 percent as shown in Table 1.

Table 1. Experts Evaluation on Content Validity towards Instrument

\begin{tabular}{lllllll}
\hline Expert & Expert 1 & Expert 2 & Expert 3 & Expert 4 & Expert 5 & Overall mean \\
\hline Percentage & 67.5 & 88.9 & 97.5 & 100.0 & 83.3 & 87.4 \\
\hline
\end{tabular}

\subsection{Factor Analysis Results}

The findings of Table 2 reveals three factors has reappeared and explained 88.0 percent of the total variance for this sample. The first factor consists of eight items and explained 80.5 percent of the variance in the construct of the new label as "Interpersonal Communication". These factors were divided into two parts as well as "facilitation" construct of three items, and the factor of "Inspiration" which consists of five items. The second factor consists of three items that were explained 7.5 percent in constructs called "Guidance in Work".

The results of Table 2 shows the first factor of "Interpersonal Communication" has eight items $(\mathrm{C} 5, \mathrm{C} 6, \mathrm{C} 7, \mathrm{C} 9, \mathrm{C} 10, \mathrm{C} 11, \mathrm{C} 12$, and $\mathrm{C} 13)$ and has earned the loading factor of $.784, .797, .843,840, .872, .892, .864$, and .835 . These factors are divided into two dimensions of "Facilitation" and "Inspiration". Dimension "facilitation" consists of three items, namely C7, C6, C5 and while dimension "Inspiration" consists of five items, namely 
$\mathrm{C} 11, \mathrm{C} 10, \mathrm{C} 12, \mathrm{C} 9$, and $\mathrm{C} 13$. The second factor is "Guidance in Work" contains four items $(\mathrm{C} 2, \mathrm{C} 1, \mathrm{C} 3$, and $\mathrm{C} 4)$ have a capacity factor of $.854, .870, .843$, and .742 .

\subsection{Reliability Analysis}

The reliability obtained for this study to the whole is as high as 0.978 . The items that measure the dimension of guidance have Cronbach's Alpha of 0.634. In addition, three items each to measure the dimensions of facilitation and inspiration with the reliability of 0.949 and 0.964 . Therefore, these items into Malay translation have proven reliability and validity convincing study by Heslin et al. (2006). Through factor analysis, a total of one item was dropped from the instruments of $\mathrm{C} 8$.

Table 2. Factor Analysis Result for Coaching Communication Instrument (N=251)

\begin{tabular}{|c|c|c|c|}
\hline Num. & Item Description & 1 & 2 \\
\hline & \multicolumn{3}{|l|}{ Factor 1: Interpersonal Communication } \\
\hline & \multicolumn{3}{|l|}{ Dimension 1: Facilitation } \\
\hline $\mathrm{C} 7$ & Encourage me to explore new alternatives. & .823 & \\
\hline C6 & Facilitate my creative thinking to help solve the problem. & .797 & \\
\hline \multirow[t]{2}{*}{$\mathrm{C} 5$} & Act as my listener to develop my ideas. & .784 & \\
\hline & \multicolumn{3}{|l|}{ Dimension 2: Inspiration } \\
\hline $\mathrm{C} 11$ & Encourage me to develop sustainably. & .892 & \\
\hline $\mathrm{C} 10$ & Express confidence that my work performance can be improved. & .872 & \\
\hline $\mathrm{C} 12$ & Encourage me to continue to make continuous improvements. & .864 & \\
\hline C9 & Express confidence that I could thrive. & .840 & \\
\hline \multirow[t]{2}{*}{$\mathrm{C} 13$} & Supported me in taking on new challenges. & .835 & \\
\hline & \multicolumn{3}{|l|}{ Factor 2: Guidance in Work } \\
\hline $\mathrm{C} 2$ & Help me to analyze my performance. & & .870 \\
\hline $\mathrm{C} 1$ & Provide guidance on the expected performance of my job. & & .854 \\
\hline $\mathrm{C} 3$ & Provide constructive feedback about the aspects that I need to improve. & & .843 \\
\hline $\mathrm{C} 4$ & Offer useful suggestions about how I can improve my performance. & & .742 \\
\hline \multicolumn{2}{|c|}{ Eagenvalues } & 10.5 & 1.0 \\
\hline \multicolumn{2}{|c|}{ Explained variance in percentage } & 80.5 & 7.5 \\
\hline \multicolumn{4}{|c|}{ Kaiser-Meyer-Olkin $=.947$} \\
\hline \multicolumn{4}{|c|}{ Bartlett's Test of Sphericity Approx. Chi Square $=5205.334, \mathrm{df}=78, \mathrm{Sig}=.000$} \\
\hline \multicolumn{4}{|c|}{$\%$ Total variance $=88.0 \%$} \\
\hline \multicolumn{2}{|c|}{ Cronbach's Alpha } & .983 & .949 \\
\hline
\end{tabular}

Note: Leader refers to Program Coordinator / Course Coordinator. 


\subsection{The Influence of Coaching Communication towards Teaching Self-Efficacy}

To identify the significant predictive dimension of coaching communication towards teaching self-efficacy, multiple regression analysis was used to measure the contribution or influence on the self-efficacy of teaching. Table 3 shows the results of multiple regressions for the influence of coaching communication towards teaching efficacy.

The result of multiple regression showed that each dimension of coaching communication as well as guidance $\left(\mathrm{R}^{2}=.310, \mathrm{p}<.01\right)$, facilitation $\left(\mathrm{R}^{2}=.292, \mathrm{p}<.01\right)$ and inspiration $\left(\mathrm{R}^{2}=.308\right.$, $\mathrm{p}<.01)$ significantly contributed to the variance of teaching self-efficacy. These results have clearly demonstrated the positive influence of communication coaching and teaching self-efficacy significantly among educators.

Table 3. Influence of Coaching Communication on Teaching Self-Efficacy

\begin{tabular}{cccc}
\hline Dependent variable & \multicolumn{3}{c}{$\begin{array}{c}\text { Independent variable: } \\
\text { Coaching Communication }\end{array}$} \\
\cline { 2 - 4 } & Guidance & Facilitation & Inspiration \\
\hline Self-Efficacy of Teaching & $.341^{*}$ & $.338^{*}$ & $.379^{*}$ \\
F Value & 26.39 & 23.22 & 26.04 \\
$\mathrm{R}^{2}$ & .310 & .292 & .308 \\
Adjusted $\mathrm{R}^{2}$ & .096 & .085 & .095 \\
\hline
\end{tabular}

Note: $\mathrm{N}=251 ; * \mathrm{p}<.01$

\section{Discussion}

The findings showed that coaching communication has influence significantly on teaching self-efficacy. The three-dimensional coaching communication - guidance $(\beta=.341, \mathrm{p}<.01)$, facilitation $(\beta=.338, p<.01)$, and inspiration $(\beta=.379, \mathrm{p}<.01)$. Dimension of guidance contributes 31 percent to the variance of teaching self-efficacy. This was followed by facilitation and inspiration respectively to 29.2 percent and 30.8 percent of the variance of self-efficacy of teaching. The finding is consistent with studies Borman and Brush (1993) and Yukl (2002) in which coaching communication plays a vital role in the initiatives performance management to improve the effectiveness of development potential employees (Smither, London, Flautt, Vargas, \& Kucine, 2003).

\section{Research Implication}

The findings of this study lead to several implications for the improvement of teaching self-efficacy in educational organizations in Malaysia. The notion of communication practice guidance can increase the frequency and quality of the work is not something new. However, it should be noted that coaching communication is not "one-time, one-way" engagement but rather a continuous process of collaboration as described by London and Smither (2002). In other words, the quality of communication is very different mentoring by practitioners and recipients. Thus, in practice, education practitioners can use the instruments of communication guidance to get a better understanding of the extent to which communication 
practices guidance has been practiced in their organization. Although the dimensions of guidance, facilitation, and inspire more seen as a psychological elements by some parties, but there is no doubt that the psychological management of the organization has become a field that is to be given focus in increasing the potential followers.

\section{Conclusion}

This study aims to report on the validity and reliability of the items in the instruments of coaching communication used to measure the behavior of the leaders in helping their followers to improve performance and develop potential trainers within the organization of education in Malaysia. This study has used the original instrument developed by Heslin et al. (2006), which has 13 items. These instruments have been analyzed by experts' validity and exploratory factor analysis. Eigenvalues indicate the items of this questionnaire consist of three factors with a total variance accounted for 88.0 percent. Only 12 items are acceptable and one item was dropped from the translation of these instruments. Factor analysis of the 12 items produced has established three main factors, namely facilitation, inspiration, and guidance in work as recommended by Heslin et al. (2006).

The study also showed the good reliability to measure the perception of the lecturers on the behavior of their leaders. The overall reliability is 0.978 , while for all the dimensions are in between 0.634 to 0.964 . Therefore, these items are suitable for use in exploratory research. Next, the results of this study also found that the influence of communication guidance on teaching self-efficacy. Therefore, efforts should be taken by the management to form a continuous interaction process of communication that guidance created in the mutual interest of the organization. Researchers also hope that further research can contribute more in relation to the coaching communication practices and self-efficacy of teaching by focusing on the quality of the relationship between practitioner and recipient.

\section{References}

Aryl, D., Jacobs, L. C., \& Sorensen, C. (2010). Introduction to research in education. Canada: Wadsworth Cengage Learning.

Azizi Yahaya, Shahrin Hashim, Jamaludin Ramli, Yusof Boon, \& Abdul Rahim Hamdan. (2007). Menguasai penyelidikan dalam pendidikan (2nd ed.). Kuala Lumpur: PTS Professional Publishing Sdn. Bhd.

Bacon, T. (2003). Helping people change. Industrial and Commercial Training, 35(2), 73-77. http://dx.doi.org/10.1108/00197850310463797

Borman, W. C. (1993). More progress toward a taxonomy of managerial performance requirements. Human Performance, 6, 1-21. http://dx.doi.org/10.1207/s15327043hup0601_1

Chua, Y. P. (2006). Kaedah dan statistik penyelidikan: Asas statistik penyelidikan. Malaysia: McGraw-Hill. 
Flowers, C. (2006). Confirmatory factor analysis of scores on the clinical experience rubric: A measure of dispositions for preservice teachers. Educational and Psychological Measurement, 66(3), 478-488. http://dx.doi.org/10.1177/0013164405282458

Fournies, F. F. (1999). Why employees don't do what they are supposed to do and what to do about it (Revised Ed.). New York: McGraw-Hill.

Heslin, P. A., VandeWalle, D., \& Latham, G. F. (2006). Keen to help? Managers' implicit person theories and their subsequent employee coaching. Personnel Psychology, 59, 871-902. http://dx.doi.org/10.1111/j.1744-6570.2006.00057.x

Ives, Y. (2008). What is coaching? An exploration of conflicting paradigms. International Journal of Evidence Based Coaching and Mentoring, 6(2), 100-113.

Kopelman, R. E. (1986). Objective feedback. In E. A. Locke (Ed.), Generalizing from laboratory to field settings (pp. 119-145). Lexington, MA: Lexington Books.

London, M., \& Smither, J. W. (2002). Feedback orientation, feedback culture, and the longitudinal performance management process. Human Resource Management Review, 12, 81-100. http://dx.doi.org/10.1016/S1053-4822(01)00043-2

Mohd Baharudin Othman \& Mohd Khairie Ahmad. (2003). Pengantar komunikasi. Sintok: Penerbit Universiti Utara Malaysia.

Morgeson, F. P. (2005). The external leadership of self-managing teams: Intervening in the context of novel and disruptive events. Journal of Applied Psychology, 90, 497-508. http://dx.doi.org/10.1037/0021-9010.90.3.497

Raja Roslan Bin Raja Abd. Rahman, Azizi Yahaya, \& Mohd. Salleh Hj. Hassan. (2008). Peranan komunikasi kepemimpinan diri dan organisasi dalam perspektif Islam. In: Seminar Kebangsaan Kemahiran Insaniah Dan Kesejahteraan Sosial, 18-19 Ogos 2008. Mahkota Hotel Melaka.

Shamir, B., House, R. J., \& Arthur, M. B. (1993). The motivational effects of charismatic leadership. Organizational Science, 4, 577-594. http://dx.doi.org/10.1287/orsc.4.4.577

Shea, C. M., \& Howell, J. M. (1999). Charisma leadership and task feedback: A laboratory study of their effects on self efficacy and task performance. Leadership Quarterly, 10(3), 375-396. http://dx.doi.org/10.1016/S1048-9843(99)00020-X

Smither, J. W., London, M., Flautt, R., Vargas, Y., \& Kucine, I. (2003). Can working with an executive coach improve multisource feedback ratings over time? A quasi-experimental field study. Personnel Psychology, 23-44. http://dx.doi.org/10.1111/j.1744-6570.2003.tb00142.x

Sulaiman Masri \& Ahmad Khair Mohd Nor. (2005). Komunikasi pejabat. Kuala Lumpur: Utusan Publications \& Distributors Sdn Bhd.

Tabachnick, B. G., \& Fidell, L. (2007). Using multivariate statistic. Boston: Allyn and Bacon. 


\section{Macrothink}

Journal of Studies in Education ISSN 2162-6952 2014, Vol. 4, No. 4

Whitmore, J. (2002). Coaching for performance (3rd ed.). London: Nicholas Brealey.

Wilson, C. (2011). Developing a coaching culture. Industrial and Commercial Training, 43(7), 407-414. http://dx.doi.org/10.1108/00197851111171827

Yu, L. (2007). The benefits of a coaching culture. MIT Sloan Management Review, 48, 6.30-40.

Yukl, G. (2002). Leadership in organizations. Upper Saddle River, NJ: Prentice Hall. 